\title{
Three-dimensional spiral CT measurement of atlantal pedicle and its clinical application
}

\author{
WENGUI XIE, PENGFEI GAO and LIXIN JI
}

Department of Spinal Surgery, North Medical District of Linyi People's Hospital, Linyi, Shandong 276005, P.R. China

Received March 14, 2017; Accepted June 19, 2017

DOI: $10.3892 /$ etm.2017.4710

\begin{abstract}
The study aimed to establish the safe placement area and corresponding entry angle of atlantal pedicle screw using axial computed tomography (CT) measurement of atlas, in order to guide the clinical operation. Spiral thin-slice CT scan of atlas and three-dimensional reconstruction of 38 patients were randomly selected. Screw placement space was defined as the distance between the tangent lines of entry channel on the atlantal cross section and inner edge of transverse foramen and outer edge of spinal canal. Before operation, spiral CT measurement was used to determine the safe placement area, and the pipeline dredge method was used to conduct the internal fixation of atlantal pedicle screw for 7 patients. In CT measurements, the width of pedicle was $9.15 \pm 2.57 \mathrm{~mm}$, which could safely accommodate screws with the diameter of $3.5 \mathrm{~mm}$. The safe placement area was located in posterior arch of atlas (18.35 \pm 2.86 to $25.26 \pm 1.76 \mathrm{~mm}$ ) away from the posterior tubercle, the entry angle ranged from $9.09 \pm 7.45^{\circ}$ outward to $18.72 \pm 17.42^{\circ}$ inward, and the length of screw channel ranged from $26.20 \pm 2.69$ to $27.04 \pm 2.51 \mathrm{~mm}$. The width of the safe placement area was up to $6.91 \pm 7.66 \mathrm{~mm}$, and the angle of inclination on cross section was up to $27.81 \pm 10.32^{\circ}$. In conclusion, we identified a safe placement area for atlantal pedicle screw, where the screw was implanted inwards and outwards according to different entry points within the safe placement area. The detailed preoperative image measurement, determination of safe placement area and individual screw placement were found to be the key to a successful surgery.
\end{abstract}

\section{Introduction}

Atlantoaxial vertebra is the joint part of skull and spine, characterized as a unique and complex anatomical structure. There is an extension of cervical cord and medulla oblongata in spinal canal. There are important structures, such as vertebral artery,

Correspondence to: Mr. Pengfei Gao, Department of Spinal Surgery, North Medical District of Linyi People's Hospital, 129 The North of Yimeng Road, Linyi, Shandong 276005, P.R. China

Email: gkn6tv@163.com

Key words: atlas, pedicle screw, imaging data, measurement nerve root and venous plexus, outside the spinal canal (1). The stability is mainly maintained by the ligaments between ring pillow and ring axis. Trauma, inflammation, congenital malformations and tumors are among the main causes of instability (2). Stability may be recovered only by internal fixation with bone graft fusion because of its large mobility and lack of self-repairing capacity.

With the constant progress in building new internal fixation devices in recent years, a variety of methods have been developed for atlantoaxial internal fixation with bone graft fusion. Atlantal pedicle screw internal fixation surgery is characterized by small injury and wide indications, and a large number of anatomical and imaging measurements have been completed (3). The entry points are selected outward, the entry angle on cross section is generally inward or vertical, and the exposure area of posterior arch of atlas is large with high risk of injury and single entry point. Chen et al (4) suggested the safe placement area, but only selected the placement direction in the leaning angle of 0 and $10^{\circ}$. The present study aimed to identify the safe placement area and possibility of outward fixation for atlantal pedicle screw placement via computed tomography (CT) measurement, and to establish the individual measurement method for intraoperative positioning. This may facilitate the preoperative plan, reduce the incidence of surgical complications, be applied clinically and produce excellent results. The entry point and pedicle of pedicle screw were easily exposed, and the screw may be directly implanted visually, as long as the extension of vertebral artery and pedicle deformity were excluded before operation. Resnick and Benzel method may be used as long as mastering the entry point and direction, which was not the case in the present study (5).

\section{Materials and methods}

Materials. Atlantal spiral CT (scan slice thickness of $1 \mathrm{~mm}$ ) of 38 patients was used in the present study. There were 31 males and 7 females aged 24-80 years (average age, 48.7 years). Axial spiral CT films with entry channel in the middle of left and right pedicles were used. A vernier caliper (Nanjing New and High Technology Industry Development Zone, Jiangsu, China) accurate to $0.02 \mathrm{~mm}$ and protractor (accurate to $0.1^{\circ}$ ).

Measurement contents and methods

Screw placement space. Screw accreta space (SAS) was defined as the distance between the tangent lines of entry 
channel on the atlantal cross section and inner edge of transverse foramen and outer edge of spinal canal.

Determination of safety placement area (SPA). The line of anterior and posterior tubercles of atlas was taken as the middle line of atlas, the parallel to middle line was made across the outer edge of spinal canal and inner edge of transverse foramen, and the intersections with posterior arch were A1 and A2. SPA should not exceed the range of A1-A2. Pedicle width was defined as the minimum distance from the outer edge of the spinal canal to the inner edge of transverse foramen, and the outer boundary was defined as the intersection of the perpendicular bisector of the above line and posterior arch of atlas. If this intersection was on the outside of the intersection of the parallel line to the atlas middle line crossing the inner edge of transverse foramen and posterior arch (A2), the latter was defined as the external boundary. The inner boundary was defined as the intersection of central axis of screw channel and posterior arch of atlas when the placement space was $5 \mathrm{~mm}$. If this intersection was on the inside of the intersection of the parallel line to atlas middle line crossing the outer edge of spinal canal and posterior arch (A1), the latter was defined as the internal boundary (Fig. 1).

SPA measurement. The distance between the inner and outer boundaries of SPA and the posterior tubercle of atlas, the distance between the inner and outer boundaries, the entry angle and the length of entry channel, the width of atlantal pedicle and the minimum SAS within SPA were measured.

\section{Clinical application}

General information. From March 2010 to June 2012, 7 patients received the atlantal pedicle screw internal fixation (14 pieces). There were 6 males and 1 female aged 26-55 years (average age, 40.57 years). There were 3 cases of Anderson II-type fracture of the odontoid process (comminuted) (including 1 case of failed anterior hollow screw operation), 1 case of old odontoid fracture, 1 case of transverse atlantal ligament disruption, 1 case of os odontoideum and 1 case of atlantoaxial intraspinal tumor.

Preoperative preparation. Before operation, all the patients routinely received the atlantoaxial mouth-open and cervical lateral X-ray examination, as well as left and right oblique and flexion-extension X-ray examination for non-fresh fractures. The results obtained through examination, revealed a poor atlantoaxial stability in all the patients. Standard lateral film was used to measure the bone thickness of basilar part of vertebral artery groove. Upper cervical spinal CT scan and three-dimensional reconstruction were performed to observe other malformations, measure the height of posterior arch of atlas and related data regarding SPA of atlantal pedicle. Magnetic resonance imaging (MRI) examination was used to determine the situation of intraspinal spinal cord. No pedicle dysplasia was detected in any of the patients, and the height of posterior arch as well as the bone thickness of basilar part of vertebral artery groove were $>4 \mathrm{~mm}$.

Surgical methods. Under general anesthesia, neck was kept in a slightly flexed position. The median incision was made to expose the posterior arch of atlas, and the posterior arch was separated along the posterior periosteum until the measurement range. The upper and lower posterior arch of atlas was probed using a nerve detacher, followed by subperiosteal

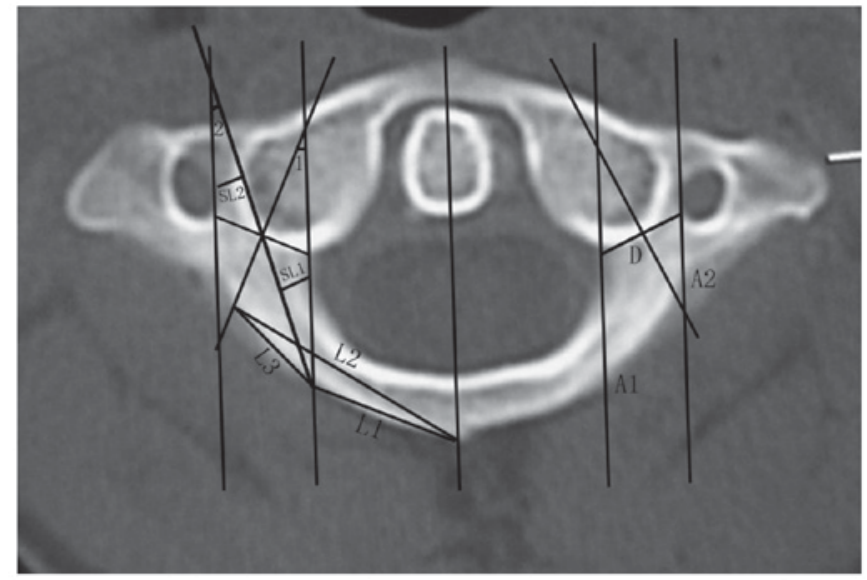

Figure 1. Determination of SPA. D, pedicle width; L1, distance between posterior tubercle and internal boundary point of SPA; L2, distance between posterior tubercle and external boundary point of SPA; L3, distance between SPA and internal and external boundary points; SL1, minimum distance between entry channel axis and outer edge of spinal canal; SL2, minimum distance between entry channel axis and inner edge of transverse foramen; SL1 + SL2, SAS distance; maximum inclined angle, $<1$; maximum camber angle, $<2$. SPA, safety placement area.

dissection, in order to fully expose the entrance of atlantal pedicle. The approximate locations of inner edge and lateral mass of posterior arch of atlas were detected via a nerve detacher. Using the SPA data measured before operation, the entry point in posterior arch was selected and cortical bone was rubbed off using abrasive drilling to expose the entrance of pedicle. According to the preoperative measurement, the entry direction was selected, and the cancellous bone was scraped away using curette (diameter, $2 \mathrm{~mm}$ ). Walls of pedicle screw channel were detected at any time, and if any issue occurred, the direction was adjusted. The screw channel was detected using probe along the pedicle screw channel until approximately $15 \mathrm{~mm}$ length was drilled, and the surrounding bone suggested that the screw position was good. The hole was drilled using pointed cone (diameter, $2.5 \mathrm{~mm}$ ) until the measurement length without breaking the anterior bone cortex, and the hole was expanded slowly using the screw tap (diameter, $3.0 \mathrm{~mm}$ ). The probe was used again to detect the walls of pedicle screw channel to confirm its integrity, and a screw (diameter, $3.5 \mathrm{~mm}$ ) was screwed into the channel. Using the preoperative measurements, the pedicle screw was screwed into the channel, and titanium rod was pre-bended and used to lift and fix the dislocation according to the size of atlantoaxial dislocation. We also determined whether foramen magnum decompression and posterior arch of atlas was needed. The rough surfaces of posterior arch of atlas, vertebral plate and spinous process cortex were grounded, followed by bone graft fusion as well as routine placement and drainage.

Statistical analysis. We used SPSS 19.0 statistical software for our statistical analyses. Data were presented as mean \pm standard deviation (mean $\pm \mathrm{SD}$ ) and t-test was used for the comparison of data on the left and right sides. $\mathrm{P}<0.05$ was considered to indicate a statistically significant difference. 
Table I. CT image measurement.

\begin{tabular}{|c|c|c|c|}
\hline Parameters & $\begin{array}{l}\text { Left } \\
\text { side }\end{array}$ & $\begin{array}{l}\text { Right } \\
\text { side }\end{array}$ & $\begin{array}{l}\text { Two } \\
\text { sides }\end{array}$ \\
\hline Pedicle width (mm) & $\begin{array}{c}9.41 \pm 3.37 \\
(5.04-27.43)\end{array}$ & $\begin{array}{c}8.89 \pm 1.36 \\
(5.47-12.30)\end{array}$ & $9.15 \pm 2.57$ \\
\hline $\begin{array}{l}\text { Maximum entry angle } \\
\text { inward on cross } \\
\text { section }\left({ }^{\circ}\right)\end{array}$ & $\begin{array}{c}18.3 \pm 5.7 \\
(5.1-29.3)\end{array}$ & $\begin{array}{c}19.1 \pm 5.7 \\
(2.4-31.4)\end{array}$ & $18.72 \pm 17.42$ \\
\hline $\begin{array}{l}\text { Screw channel length } \\
\text { under the maximum } \\
\text { leaning angle (mm) }\end{array}$ & $\begin{array}{c}25.85 \pm 2.87 \\
(18.97-31.87)\end{array}$ & $\begin{array}{c}26.55 \pm 2.48 \\
(19.32-30.39)\end{array}$ & $26.20 \pm 2.69$ \\
\hline $\begin{array}{l}\text { Distance from external } \\
\text { boundary of SPA to } \\
\text { posterior tubercle }(\mathrm{mm})\end{array}$ & $\begin{array}{c}25.47 \pm 1.94 \\
(19.50-29.10)\end{array}$ & $\begin{array}{c}25.06 \pm 1.56 \\
(22.08-28.99)\end{array}$ & $25.26 \pm 1.76$ \\
\hline $\begin{array}{l}\text { Minimum entry angle } \\
\text { on cross section }\left(^{\circ}\right)\end{array}$ & $\begin{array}{c}-9.1 \pm 7.6 \\
(-23.9-9.4)\end{array}$ & $\begin{array}{c}-9.1 \pm 7.4 \\
(-20.6-15.8)\end{array}$ & $-9.09 \pm 7.45$ \\
\hline $\begin{array}{l}\text { Screw channel length } \\
\text { under the minimum } \\
\text { entry angle }(\mathrm{mm})\end{array}$ & $\begin{array}{c}27.31 \pm 2.62 \\
(21.48-31.60)\end{array}$ & $\begin{array}{c}26.76 \pm 2.39 \\
(21.27-31.74)\end{array}$ & $27.04 \pm 2.51$ \\
\hline $\begin{array}{l}\text { Distance from internal } \\
\text { boundary of SPA to } \\
\text { posterior tubercle }(\mathrm{mm})\end{array}$ & $\begin{array}{c}18.52 \pm 2.89 \\
(13.26-27.95)\end{array}$ & $\begin{array}{c}18.18 \pm 2.85 \\
(13.54-27.69)\end{array}$ & $18.35 \pm 2.86$ \\
\hline $\begin{array}{l}\text { Screw channel width } \\
\text { under the minimum } \\
\text { entry angle }(\mathrm{mm})\end{array}$ & $\begin{array}{c}5.37 \pm 0.94 \\
(3.08-9.78)\end{array}$ & $\begin{array}{c}5.43 \pm 0.74 \\
(3.96-7.05)\end{array}$ & $5.40 \pm 0.84$ \\
\hline $\begin{array}{l}\text { Distance from internal } \\
\text { boundary to external } \\
\text { boundary of SPA }(\mathrm{mm})\end{array}$ & $\begin{array}{l}6.95 \pm 2.82 \\
(0-14.53)\end{array}$ & $\begin{array}{l}6.87 \pm 2.59 \\
(0-10.35)\end{array}$ & $6.91 \pm 7.66$ \\
\hline $\begin{array}{l}\text { Entry angle range } \\
\text { in SPA }\left(^{\circ}\right)\end{array}$ & $\begin{array}{c}27.37 \pm 10.69 \\
(0-44.2)\end{array}$ & $\begin{array}{l}28.25 \pm 10.06 \\
(0-43.6)\end{array}$ & $27.81 \pm 10.32$ \\
\hline
\end{tabular}

$\mathrm{p}>0.05$, and the differences of data on left and right sides were not statistically significant, so they were calculated jointly; minimal values and maximal values were in brackets. CT, computed tomography.

\section{Results}

CT image measurement results. The camber angle was negative and the width of pedicle was $\sim 9.15 \pm 2.57 \mathrm{~mm}$, which was able to safely accommodate $3.5 \mathrm{~mm}$ diameter screws (Table I). SPA was located in posterior arch of atlas. It was $18.35 \pm 2.86$ to $25.26 \pm 1.76 \mathrm{~mm}$ away from the posterior tubercle, the entry angle was ranged from $-9.09 \pm 7.45^{\circ}$ outward to $18.72 \pm 17.42^{\circ}$ inward, and the length of screw channel ranged from $26.20 \pm 2.69$ to $27.04 \pm 2.51 \mathrm{~mm}$. The width of SPA was up to $6.91 \pm 7.66 \mathrm{~mm}$ on posterior arch, and the entry angle on cross section was up to $27.81 \pm 10.32^{\circ}$. There were some individual differences. There were two cases $(5.26 \%)$ with the pedicle width of $\sim 5 \mathrm{~mm}$ on four sides and in three cases $(5.26 \%)$ we observed the pedicle width of $\sim 5 \mathrm{~mm}$ on four sides but SAS width within SPA of $<5 \mathrm{~mm}$. Over $10 \%$ of the cases were not suitable for pedicle fixation. There was one case with the smallest left vertebral artery foramen and pedicle width of $27.43 \mathrm{~mm}$, indicating the abnormal vertebral artery shape.

Clinical application results. The total amount of bleeding in all patients, during the operation, ranged from 60 to $300 \mathrm{ml}$ for
90-120 min. Patients did not suffer any injury to their vertebral artery, nerve root and spinal cord. Postoperative lateral side X-ray photograph and spiral CT examination for cervical spine showed that 14 pedicle screws had the ideal position within SPA measured before operation, and there was no perforation of the pedicle bone cortex. During the postoperative follow-up for 6 to 12 months, there was no internal fixation loosening and fracture. After the bone grafting, all 7 patients had the bone fusion. Figs. 2 and 3 showed pre- and post-operation images for two typical cased with odontoid fractures.

\section{Discussion}

Anatomical basis of atlantal pedicle internal fixation. Atlas has a special anatomical structure, where the bone ring is composed of the anterior arch, posterior arch and two lateral masses and transverse process without vertebral body and spinous process but with huge lateral masses on both sides. The connection part of posterior arch of atlas and lateral mass is similar to the pedicle of other vertebrae in structure and mechanics. The posterior arch of atlas is fixed by the pedicle screw, which is referred to as the atlantal pedicle screw by Resnick and Benzel (5). Ma et al (6) suggested that the vertebral artery groove was the weakest in the structural mechanics and anatomy of atlas, which is termed as the 'isthmus' of atlas. Tan et al (7) observed 50 cases of vertebral artery grooves, including 2 sides of nongroove type, 83 sides of shallow groove type, 7 sides of deep groove type and 8 sides of ring groove type ( 2 sides of full-ring type and 6 sides of half-ring type), and the deep groove type and ring groove type accounted for $15 \%$. The vertebral artery of ring-type vertebral artery groove is actually embedded in the bone tube, and the upper edge of bone tube may be mistaken as the upper edge of posterior arch, causing the injury to vertebral artery. The bone thickness at the bottom part of deep-type vertebral artery groove is small, and vertebral artery may also be damaged during the entry via posterior arch. There are two commonly accepted theories to explain the possible causes of atlantal artery groove ring, congenital malformations and acquired atlanto-occipital ligament ossification (8).

Feasibility of atlantal pedicle screw fixation. Atlas connects the skull and spine, and atlantoaxial dislocation or atlanto-occipital instability may directly oppress the medulla oblongata and endanger the lives of patients. Therefore, the stability reconstruction of atlas is essential. Prior studies have suggested that the cervical spine screw fixation technique is the three-column fixation (9). A large number of studies have shown that its biomechanical stability is significantly superior to the conventional cervical anterior plate fixation, posterior lateral mass fixation and anterior-posterior combined fixation (10). Atlantoaxial screw fixation technique introduced by Magerl and Seemann reported a better biomechanical stability (especially the rotary stability) (11). The bone graft fusion rate has been reported to be close to $100 \%$ via the clinical combination of posterior wire fixation (12). However, this operation had no advantage in the anti-axial displacement, and the complete restoration was needed before screw placement, thus the risk of vertebral artery and sublingual nerve injury was large. In addition, this method was not appropriate for obese patients and those with thoracic kyphosis, barrel chest and other diseases in which the cervical 


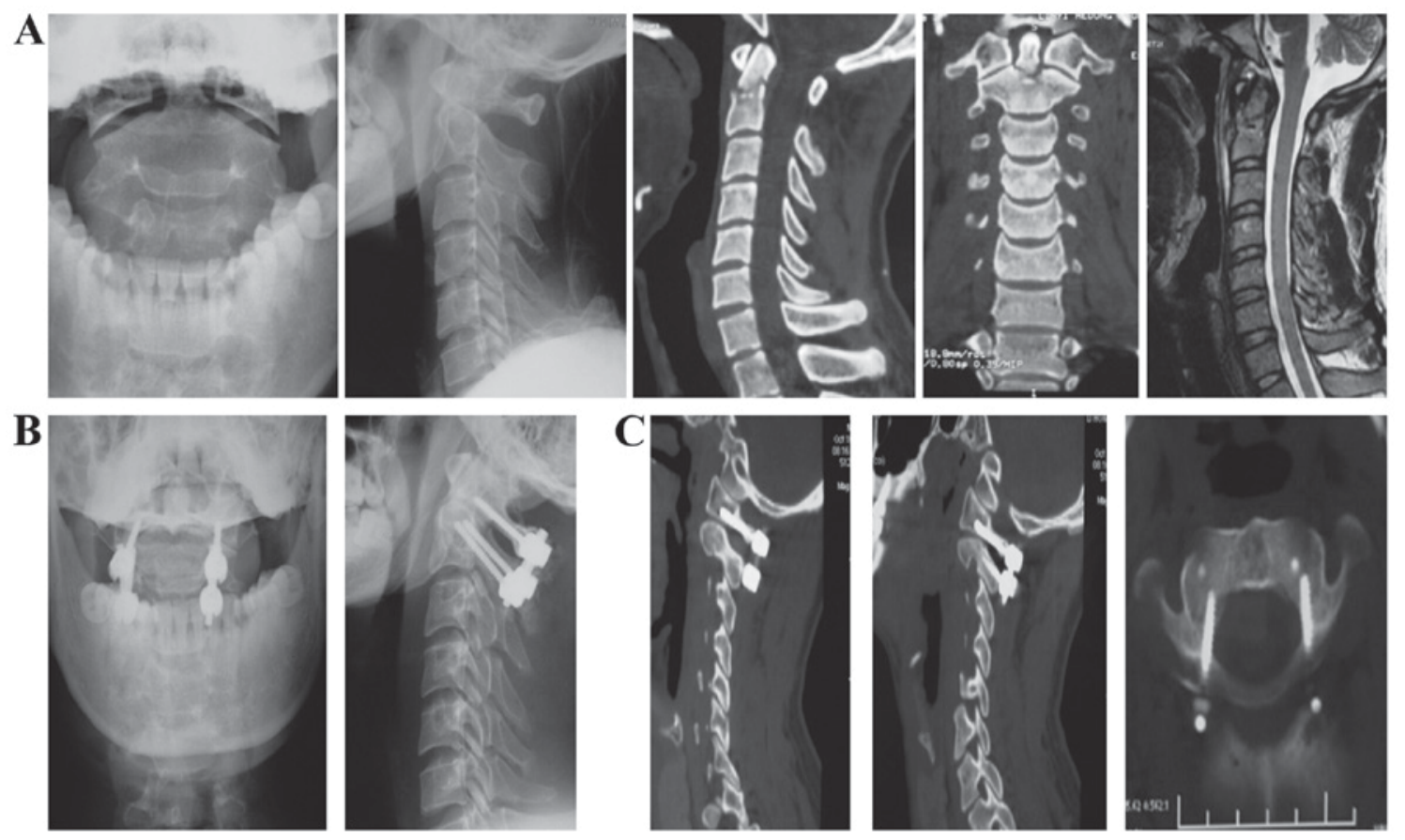

Figure 2. Typical case 1: Male, 28 years; failed anterior fracture operation of odontoid process of axis. (A) Before operation, (B) postoperative X-ray and (C) postoperative CT. CT, computed tomography.
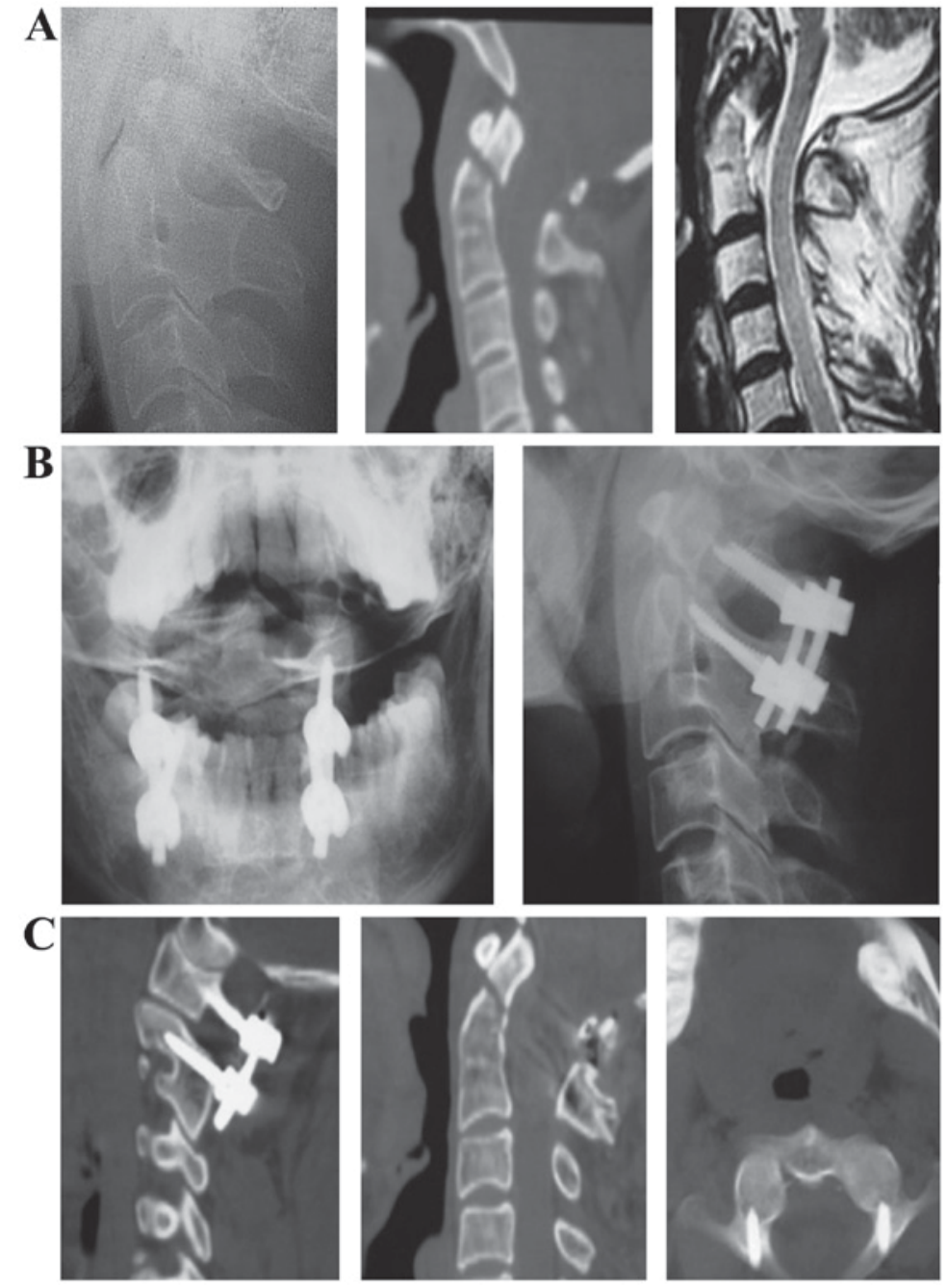

Figure 3. Typical case 2: Male, 43 years; fracture of the odontoid process, and segmentation of C2-C3. (A) Before operation, (B) postoperative X-ray and (C) postoperative CT. CT, computed tomography. 
spine could not bend excessively. In 1994, Goel and Laheri (13) reported the atlantal lateral mass screw technique for the first time, and Harms and Melcher (14) reported the application of atlantoaxial lateral mass screw fixation technique in 2001. When applying this technique, $\mathrm{C} 2$ nerve root and peripheral venous plexus should be retracted, and C2 nerve root was cut off, which may lead to nerve damage or bleeding. Resnick and Benzel (5) reported that the atlantal lateral mass could accommodate the lateral mass screw with the diameter of up to $7 \mathrm{~mm}$. Resnick et al (15) first reported one atlantoaxial pedicle screw technique, and treated one female patient for whom the Magerl technique was not suitable. Through a large number of anatomical and imaging measurements and biomechanical studies, Chinese scholars have argued that atlantal pedicle has the conditions of screw placement. When using pedicle screw technique, the lateral mass and anatomical structure of posterior arch do not need to be peeled off, and it is easier to push away the $\mathrm{C} 2$ nerve root and venous plexus, thus the risk of injury is reduced with less bleeding, longer screw channel than lateral mass screw and firmer fixation (16).

Anatomical measurement of atlantal lateral mass and pedicle screw channel. Tan et al (17) measured the dry atlas bones in 50 adults, and reported that the middle height of lateral mass was $13.02 \pm 1.18 \mathrm{~mm} / 13.11 \pm 1.23 \mathrm{~mm}$ (left/right, the same below), the transverse diameter of lateral mass was $11.52 \pm 2.97 \mathrm{~mm} / 11.76 \pm 2.97 \mathrm{~mm}$, the posterior arch height at the bottom of vertebral artery groove was $4.58 \pm 0.65 \mathrm{~mm} / 4.72 \pm 0.68 \mathrm{~mm}$, and the posterior arch height at the entry point was $5.39 \pm 1.58 \mathrm{~mm} / 11.76 \pm 2.97 \mathrm{~mm}$. The gap between entry point in channel direction and front edge of vertebral artery groove was $10.60 \pm 2.87 \mathrm{~mm} / 10.79 \pm 1.51 \mathrm{~mm}$. Xia et al (18) measured the dry atlas bones in 30 adults, and reported that the middle width of lateral mass was $11.6 \pm 1.4 \mathrm{~mm}$ and the thickness of the central point of lateral mass was $12.7 \pm 1.0 \mathrm{~mm}$, and the posterior arch thickness of vertebral artery was $4.7 \pm 1.0 \mathrm{~mm}$, meeting the requirement of inserting screw with the diameter of $3.5 \mathrm{~mm}$. A large number of anatomical data showed that atlantal lateral mass and atlantal pedicle met the requirement of internal fixation of screw with the diameter of $3.5 \mathrm{~mm}$ (19-24). Nevertheless, there were also risks of pedicle screw fixation in some cases of smaller posterior arch height. The posterior arch height in the thinnest bone at the bottom of vertebral artery groove was significantly smaller compared with that of the posterior arch width, and smaller than the posterior arch height at the entry point. The posterior arch height at this point is the key to the diameter of screw and successful operation. The pedicle width and isthmus height are the main factors limiting the placement of pedicle screw. When the pedicle screw with the diameter of $3.5 \mathrm{~mm}$ is placed, the pedicle width and isthmus height cannot be smaller than $5 \mathrm{~mm}$. The pedicle width was measured by the author; the pedicle width was $9.15 \pm 2.57 \mathrm{~mm}$, including two cases $(5.26 \%)$ with the pedicle width of $>5 \mathrm{~mm}$ on 4 sides $(5.26 \%)$. Although the pedicle width was $>5 \mathrm{~mm}$, the width of SAS within SPA was $<5 \mathrm{~mm}$.

Biomechanics of internal fixation of atlantal pedicle screw. Xia et al (25) reported that the pullout force of atlantal lateral mass posterior screw was significantly smaller than that of occipital screw, but had no significant difference with the pullout force of axis pedicle screw. Ma et al (26) suggested that the pullout force of bicortical atlantal pedicle screw fixation was the largest, and there was no significant difference in the pullout force between the monocortical atlantal pedicle screw fixation and the bicortical atlantal lateral mass fixation and monocortical pedicle screw fixation suggesting that the bicortical screw fixation should be selected in the atlantal lateral mass screw fixation, and the monocortical screw fixation should be selected in the atlantal pedicle screw fixation. Zhang et al (27) showed that the atlantal pedicle screw fixation method could provide a higher stability than atlantal lateral mass internal fixation.

Imaging measurement of atlantal pedicle screw channel. Lin et al (28) measured the atlantal CT results in 120 Chinese patients, and reported that the lateral mass thickness was approximately $12.8 \mathrm{~mm}$, the anteroposterior diameter of lateral mass was approximately $21.5 \mathrm{~mm}$, and the transverse diameter of lateral mass was $11.8-13.3 \mathrm{~mm}$, fully meeting the requirement of placing the screw with the diameter of $3.5 \mathrm{~mm}$. Tan etal (29) performed multi-section CT scan and measurement for atlantal pedicle screw fixation channel using 50 samples of atlantal bone, and the results showed that the middle height of lateral mass was $16.98 \pm 1.81 \mathrm{~mm} / 16.55 \pm 1.07 \mathrm{~mm}$, the posterior arch height at the bottom of vertebral artery groove was $4.83 \pm 0.76 \mathrm{~mm} / 4.94 \pm 0.95 \mathrm{~mm}$, the gap between the entry point in the entry direction and the anterior vertebral artery groove was $10.42 \pm 2.02 \mathrm{~mm} / 10.88 \pm 1.48 \mathrm{~mm}$, the leaning angle was approximately $0^{\circ}$ and the camber angle was approximately $5^{\circ}$, which was consistent with the caliper measurement result of dry bone. A large number of anatomical and imaging measurements of atlas showed that both of them were consistent, which could make the atlantal pedicle screw internal fixation feasible, and the entry point, direction and depth could be selected through measurement. Nevertheless, the detailed X-ray and three-dimensional spiral CT measurements provided the individualized data to guide the safe placement of atlantal pedicle screw during the operation.

Selection of entry point of atlantal pedicle screw fixation and placement technique. For the atlantal pedicle screw, the entry point should be clear and easy to determine. During the entry process, the vertebral artery in the vertebral artery groove above should be protected, the vertebral artery in transverse foramen outside should also be protected, the venous plexus between $\mathrm{C} 1$ and $\mathrm{C} 2$ and $\mathrm{C} 2$ nerve root below should be avoided as far as possible, and the spinal dura mater and spinal cord inside should be protected. The key to the atlantal pedicle screw fixation is the selection of entry point and entry angle. The entry angle on the sagittal plane can be measured through the standard cervical lateral film, 5-10 ${ }^{\circ}$ upward. Different scholars offered diverse views on the selection of entry angle and inclined angle on cross section. Tan et al (17) suggested that the entry point was defined as the intersection of $18-20 \mathrm{~mm}$ on both sides of the middle point of posterior tubercle of atlas and $2 \mathrm{~mm}$ above the lower edge of the posterior arch, and the entry direction was defined as $5^{\circ}$ vertical to the coronal plane. Wang et al (30) reviewed 159 cases of atlantal pedicle screw fixation or lateral mass fixation with complete image data, detected the inner edge of atlantal lateral mass below using nerve dissector along the vertebral pedicle, and speculated the 
entry point of atlantal pedicle or lateral mass internal fixation. Chen et al (4) measured 30 atlanto-axis with normal shape for CT thin-slice scan and three-dimensional reconstruction, and measured that SAS under the leaning angle of 0 and $10^{\circ}$ on cross section was $7.81 \pm 1.28 \mathrm{~mm}$ and $9.69 \pm 1.23 \mathrm{~mm}(>3.5 \mathrm{~mm})$. The entry point under the leaning angle of $10^{\circ}$ was $2 \mathrm{~mm}$ outward compared with that under the leaning angle of $0^{\circ}$. The results of that study showed that the entry point of atlantal lateral mass screw should also have the corresponding SPA on cross section of posterior arch, rather than a single-entry point, and the entry point and direction should be determined based on the preoperative X-ray and CT measurements. He et al (31) measured 48 dry atlas bones. According to the bone thickness at the bottom of vertebral artery groove, with the adults' atlantal pedicle screw with the diameter of $3.5 \mathrm{~mm}$ as the standard, the posterior arch can be divided into three types based on the posterior arch at the bottom of vertebral artery: i) Ordinary type, posterior arch height $>3.5 \mathrm{~mm}$ accounting for $83 \%$; ii) mild variation, posterior arch height 1.75-3.5 $\mathrm{mm}$ accounting for 13\%; and iii) severe variation, posterior arch height $<1.75 \mathrm{~mm}$ accounting for $4 \%$. During the operation, the entry method is determined according to the bone thickness at the bottom of the vertebral artery groove measured by three-dimensional spiral CT. Pedicle screw fixation can be used for the ordinary type and mild variation, but the screw is likely to break through the bone below pedicle for mild variation. The fixation of severe variant is similar to that of lateral mass screw without going through the pedicle, however, the entry point is in the intersection of lower edge of posterior arch and lateral mass, and the typical entry point of lateral mass screw is in a high position; therefore, the risk of damaging $\mathrm{C} 2$ nerve root and venous plexus is small. Tan et al (32) suggested the 'pedicle-exposed placement method'. According to preoperative imaging measurements, the entry point and direction were determined, the bone cortex was removed on the surface of entry point on posterior arch of atlas to expose the entrance of pedicle, and the hole was drilled by hand. For the height of posterior arch of atlas $<4 \mathrm{~mm}$, the vertebral artery and venous plexus above the posterior arch of atlas could be peeled off to protect the vertebral artery, expose the initial segment of lateral mass and posterior arch, and the atlantal pedicle screw with the diameter of $3.5 \mathrm{~mm}$ was placed safely using the pedicle-exposed placement method. Screw was exposed below the vertebral artery, the fascia tissue was taken above the screw, and the vertebral artery was isolated and protected.

Methods and significance of the present study. One of the keys to the success of atlantal pedicle screw is the selection of entry point and direction. Most of the above scholars chose the single-entry point, but the positioning method was different, and the entry angle was mostly $0-10^{\circ}$. Although Chen et al (4) recommended the concept of SPA, practically the inward entry was employed. Hao et al (33) suggested the anatomical measurement of outward entry, and used the corresponding posterior arch to lateral edge of spinal canal as the entry point. In this study, the possible SPA of entry point and the possible entry angle were detected through atlantal CT cross-sectional measurement, in order to guide the screw placement, achieving satisfactory results. In the measurement, posterior tubercle of atlas was taken as the reference, and the straight-line distance from posterior tubercle to entry point was measured directly to facilitate the intraoperative measurement. In the past, the vertical distance between simulated middle lines of entry point and posterior and anterior tubercle of atlas. Consequently, the intraoperative measurement was difficult with numerous errors. The entry angle on the sagittal plane of the atlantal pedicle screw was measured through the standard atlantoaxial lateral film, which is relatively simple.

To determine SPA of the atlantal pedicle screw, screw placement space was defined as the distance between the tangent lines of entry channel on atlantal cross section and inner edge of transverse foramen and outer edge of spinal canal. A large number of studies argued that to insert the screw with the diameter of $3.5 \mathrm{~mm}$ securely, the placement space of atlantal pedicle screw should be at least $5 \mathrm{~mm}$, therefore the placement space should also be $>5 \mathrm{~mm}$ (34). This could ensure the safety of screw placement and prevent the screw from breaking through the bone cortex into the spinal canal or transverse foramen. The width of atlantal pedicle is not accurately defined; thus, the author defined the pedicle width as the minimum distance from the outer edge of spinal canal to the inner edge of transverse foramen. The author also defined the outer boundary as the intersection of perpendicular bisector of the above line and posterior arch of atlas. The line of posterior and anterior tubercles of atlas was taken as the middle line of atlas, and the parallel line to middle line was made crossing the outer edge of spinal canal and inner edge of transverse foramen. If this intersection was outside the intersection of the parallel line to atlas middle line crossing the inner edge of transverse foramen and posterior arch, the latter was defined as the external boundary. The inner boundary was defined as the intersection of central axis of screw channel and posterior arch of atlas when the placement space was $5 \mathrm{~mm}$. If this intersection was inside the intersection of parallel line to atlas middle line crossing the outer edge of spinal canal and posterior arch, the latter was defined as the internal boundary.

The distance between the inner boundary of SPA of atlantal pedicle screw and posterior tubercle was approximately $18 \mathrm{~mm}$, which was greater than the radius of spinal canal measured by several scholars. The distance between the outer boundary of SPA and posterior tubercle was approximately $25 \mathrm{~mm}$, which was also greater than the entry point data reported before, which may be due to the different measurement methods used. The SPA width of the atlantal pedicle screw was approximately $7 \mathrm{~mm}$, and the entry angle within SPA ranged from $9^{\circ}$ outward to $18^{\circ}$ inward with the span of nearly $27^{\circ}$, which was safe within this range. Each entry point within SPA had a corresponding optimal entry angle. When it was closer to the lateral boundary the SAS was larger and the risk of injury to the spinal and vertebral artery was smaller. In other words, it should be exposed to the lateral boundary as far as possible during the operation, and the outer boundary of SPA should be selected as the entry point. However, if it was exposed outward, the risk of venous plexus bleeding was high. Usually bleeding was successfully controlled using hemostasis by compression, but if it was difficult to stop bleeding and impossible to expose to the posterior arch, the pedicle screw was placed according to preoperative measurement. All 7 patients in the present study, successfully received the pedicle screw placement using this method, and 
the position was proved to be ideal. When the pedicle screw was placed, the bone cortex at the entry point was ground to expose the entrance of entry channel. According to the pipeline dredge method (35), the curette with the diameter of $2 \mathrm{~mm}$ was used to remove the cancellous bone in a rotation mode along the entry direction of pedicle screw. The end of curette was the arc-shaped with single-sided blade, thus when the curette hit the cortical bone of pedicle, it could turn into the pedicle lumen with soft bone. The walls of pedicle screw channel should be detected at any time, and if it was difficult to move forward, the direction could be adjusted. Tan et al (7) reported that the gap between entry point in the direction of entry channel and anterior margin of vertebral artery was approximately $11 \mathrm{~mm}$. Therefore, $15 \mathrm{~mm}$-deep drilling reached the wide lateral mass across the isthmus, and bradawl could be used to continue drilling to the appropriate depth. The measurement results showed that the length of entry channel was $26-27 \mathrm{~mm}$, which was roughly the same as the measurement data of other scholars. There were 8 sides $(10.53 \%)$ without SPA in the group, which meant that SAS was $<5 \mathrm{~mm}$ within SPA, so pedicle screw fixation was not appropriate.

In conclusion, a large number of anatomical structure observation of atlas, measurements of lateral mass of atlas and pedicle and biomechanical studies have shown that atlas has the pedicle structure similar to other cervical vertebra with the conditions for posterior pedicle screw fixation. The results of imaging measurement, especially spiral CT and X-ray measurement, were consistent with the anatomical measurements, thus the preoperative imaging measurement could be applied to guide the operation. A large number of clinical application results have proven that the atlantal pedicle screw has the strong holding force, good stability and high bone graft fusion rate, and the operation is characterized by the short time, less bleeding and relatively simple procedure, which can be widely used in the treatment of atlantoaxial diseases. This includes Anderson II-type fractures that anterior fixation could be applied, old odontoid fractures, transverse atlantal ligament disruption, atlantoaxial dislocation, odontoid process dysplasia or os odontoideum, basilar impression, rheumatoid arthritis and atlantoaxial tumor. As long as the atlantal pedicle and lateral mass was not damaged and the preoperative measurement showed that the pedicle screw placement was feasible, atlantal pedicle screw fixation could be performed. Through the spiral CT measurement of atlantal pedicle screw, it was found the entry point of atlantal pedicle screw was not definitely one point. There was a safe placement area, and each entry point within SPA had its optimal entry angle. The detailed imaging measurement before operation could determine the individual placement area and entry angle, and bloodless operation should be performed as far as possible. Pipeline dredge method may be used in the screw channel drilling to safely place the atlantal pedicle screw.

\section{References}

1. Jiang YW, Xia H, Wang ZY, Wu ZH, Ma XY, Wei GJ, Ma LM, Huang JL, Zheng G and Feng XL: Variation of craniocervical junction volume as an effective parameter for basilar invagination treatment. Eur Rev Med Pharmacol Sci 19: 1754-1760, 2015.

2. Duan S, He H, Lv S and Chen L: Three-dimensional CT study on the anatomy of vertebral artery at atlantoaxial and intracranial segment. Surg Radiol Anat 32: 39-44, 2010.
3. Abumi K, Shono Y, Ito M, Taneichi H, Kotani Y and Kaneda K: Complications of pedicle screw fixation in reconstructive surgery of the cervical spine. Spine (Phila Pa 1976) 25: 962-969, 2000.

4. Chen Q, Shen J, Li F and Yang D: Establishment and application of safe fixation area of lateral mass of atlas. Chin J Trauma 22: 404-407, 2006 (In Chinese).

5. Resnick DK and Benzel EC: C1-C2 pedicle screw fixation with rigid cantilever beam construct: Case report and technical note. Neurosurgery 50: 426-428, 2002.

6. Ma X, Zhong S, Liu J, Yin Q, Xu D, Xia H, Wu Z and Ding Z: The anatomic study on the feasibility of posterior pedicle screw fixation on atlas. Chin J Clin Anat 21: 554-555, 2003 (In Chinese).

7. Tan M, Zhang G, Li Z, et al: Research on atlas measurement and lateral screw fixation channel via posterior Arch. Chin J Spine and Spinal Cord 12: 5-8, 2002 (In Chinese).

8. Ma X, Yin Q, Zhong S, Liu J, Xia H, Wu Z, Xu D and Ding Z: Anatomic relationship between the posterior neurovascular plexus of atlantoaxial joint and the placement of atlas pedicle screw. Chin J Clin Anat 23: 454-457, 2005 (In Chinese).

9. Abumi K, Kaneda K, Shono Y and Fujiya M: One-stage posterior decompression and reconstruction of the cervical spine by using pedicle screw fixation systems. J Neurosurg 90: 19-26, 1999.

10. Abumi K, Ito M and Sudo H: Reconstruction of the subaxial cervical spine using pedicle screw instrumentation. Spine (Phila Pa 1976) 37: E349-E356, 2012.

11. Abumi K and Kaneda K: Pedicle screw fixation for nontraumatic lesions of the cervical spine. Spine (Phila Pa 1976) 22: 1853-1863, 1997.

12. Wang C, Yan M, Zhou H, Wang S and Dang G: Atlantoaxial transarticular screw fixation with morselized autograft and without additional internal fixation: Technical description and report of 57 cases. Spine 32: 643-646, 2007.

13. Goel A and Laheri V: Plate and screw fixation for atlanto-axial subluxation. Acta Neurochir (Wien) 129: 47-53, 1994.

14. Harms J and Melcher RP: Posterior C1-C2 fusion with polyaxial screw and rod fixation. Spine 26: 2467-2471, 2001.

15. Resnick DK, Lapsiwala S and Trost GR: Anatomic suitability of the C1-C2 complex for pedicle screw fixation. Spine 27: 1494-1498, 2002.

16. Kawaguchi Y, Nakano M, Yasuda T, Seki S, Hori T and Kimura T: Development of a new technique for pedicle screw and Magerl screw insertion using a 3-dimensional image guide. Spine (Phila Pa 1976) 37: 1983-1988, 2012.

17. Tan M, Wang H, Wang Y, Zhang G, Yi P, Li Z, Wei H and Yang F: Morphometric evaluation of screw fixation in atlas via posterior arch and lateral mass. Spine 28: 888-895, 2003.

18. Xia H, Zhong S, Liu J, et al: Applied anatomy of lateral atlantoaxial posterior screw fixation. Chin J Clin Anat 20: 83-85, 2002 (In Chinese).

19. Yin D, Yuan L, Xia H and Li J: Quantitative measurements and clinical significance of lateral mass of atlas. Chin J Clin Anat 21: 241-242, 2003 (In Chinese).

20. Yan M, Wang C, Dang G, et al: Anatomical basis of internal fixation of lateral mass of atlas and isthmus of axis. Chin J Spine and Spinal Cord 13: 25-27, 2003 (In Chinese).

21. Ma X, Zhong S, Liu J, Yin Q, Xu D, Xia H and Wu Z: Anatomical measurement of lateral mass screw fixation of posterior arch of atlas. Chin J Spine and Spinal Cord 14: 23-25, 2004 (In Chinese).

22. Li G, Zuo B, Feng Z, Chen J and Lin J: Measurement of atlas and its significance for clinical application. Sichuan J Anat 18: 18-21, 2010 (In Chinese).

23. Hao D, Fang X, Wu Q, et al: Anatomical study on stability reconstruction of upper cervical spine via posterior arch of atlas. Chin J Orthoped 31: 339-342, 2011 (In Chinese).

24. Chen Q, Jin D and Xiao Z: Anatomical study on transpedicle screw fixation of atlas and axis. J Guangxi Med Univ 26: 365-368, 2009 (In Chinese).

25. Xia H, Zhong S, Liu J, et al: Feasibility research on posterior screw fixation of lateral mass of atlas. Chin J Orthoped 10: 888-891, 2002 (In Chinese).

26. Ma X, Zhao W, Yin Q, et al: Biomechanical evaluation of posterior atlantal monocortical or bicortical bone screw fixation strength. Chin J Spine and Spinal Cord 15: 34-37, 2005 (In Chinese).

27. Zhang H, Bai J, Tan M and Yi P: Biomechanical analysis of the posterior pedicle screw and the lateral mass screw on the atlas. J Tsinghua Univ (Sci Technol) 48: 419-422, 2008 (In Chinese). 
28. Lin F, Chi Y, Xu C, Chen T, Lin X and Lin Z: Anatomical measurement of atlantoaxial imaging of Chinese and its clinical significance. J Wenzhou Med Coll 34: 304-305, 2004 (In Chinese)

29. Tan M, Wang H, Zhang G, Yi P, Liang L, Wei H, Yang F and Li Z: CT measurement of the path of screw fixation in atlas via posterior arch and lateral mass. Chin J Spine and Spinal Cord 13: 28-31, 2003 (In Chinese).

30. Wang S, Wang C, Yan M, Zhou H and Dang G: Analysis of veracity of the $\mathrm{C} 1$ lateral mass screw insertion in the atlantoaxial fixation. Chin J Surg 46: 115-117, 2008 (In Chinese).

31. He F, Yin Q and Zhao T: An anatomic study of the pedicle screw fixation. Chin J Orthopaed Trauma 10: 257-259, 2008 (In Chinese)

32. Tan M, Tang X, Yi P, et al: Clinical application of atlantal pedicle screw placement technique. J Spine Surg 9: 148-152, 2011 (In Chinese).
33. Hao D, Xu Z, He B, Guo H, Liu T and Wang X: Atlantoaxial pedicle screw fixation for old odontoid fracture combined with atlantoaxial instability. Chin J Trauma 27: 121-124, 2011 (In Chinese).

34. Wang L, Liu C, Zhao Q and Tian J: Posterior pedicle screw fixation for complex atlantoaxial fractures with with atlantodental interval of $\geq 5 \mathrm{~mm}$ or $\mathrm{C} 2-\mathrm{C} 3$ angulation of $\geq 11^{\circ}$. J Orthop Surg Res 9: 104, 2014

35. Tan M, Zhang G, Yi P, Wang H, Wei H, Yang F and Li Z: Placement of cervical spine pedicle screw with dredging pipe method. Chin J Spine and Spinal Cord 12: 405-410, 2002 (In Chinese). 